\title{
Individual Differences in Cognitive Performance Regulated by Deep-Brain Activity during Mild Passive Hyperthermia and Neck Cooling
}

\author{
Emiko Imai ${ }^{*}$, Yoshitada Katagiri1,2, Hiroshi Hosaka3 ${ }^{3}$, Kiyoshi Itao4 \\ ${ }^{1}$ Department of Rehabilitation Science, Kobe University Graduate School of Health Science, Hyogo, Japan \\ ${ }^{2}$ Advanced ICT Research Institute, National Institute of Information and Communication Technology, Tokyo, \\ Japan \\ ${ }^{3}$ Graduate School of Frontier Science, The University of Tokyo, Chiba, Japan \\ ${ }^{4}$ The Advanced Institute of Wearable Environmental Information Networks, Tokyo, Japan \\ Email: *e-imai@stu.kobe-u.ac.jp
}

Received 31 March 2016; accepted 19 July 2016; published 22 July 2016

Copyright (C) 2016 by authors and Scientific Research Publishing Inc.

This work is licensed under the Creative Commons Attribution International License (CC BY). http://creativecommons.org/licenses/by/4.0/

(c) (i) Open Access

\begin{abstract}
Hyperthermia-induced decline in cognitive performance is a moderate complication that poses challenges to the maintenance of safety. Although the underlying mechanism can be attributed to the disruption of brain networks, the propensity remains unclear. This study aimed to test the hypothesis that the extent of the alterations in cognitive performance is governed by the activity of deep brain structures, including monoaminergic neural systems. A decline in cognitive performance during mild hyperthermia and the beneficial effects of neck cooling were demonstrated using the Continuous Performance Test as a battery of cognitive tasks. Aspects of cognitive performance were characterized using the deep-brain activity (DBA) index as a neural activity parameter and the State-Trait Anxiety Inventory to assess the extent of alterations in cognitive performance as an individual measure. It was found that a higher average DBA index during tasks is essential for high cognitive performance in the heat. This beneficial effect of DBA is governed by the upper brainstem. This DBA benefit is more significant for individuals with higher average DBA indices at rest in a normal environment. Individual differences in cognitive performance in the heat are governed by differences in DBA. In addition, the beneficial effect of DBA on cognitive performance in heat only applies under conditions including neck cooling. This limited neck-cooling effect is attributed to anti-homeostatic thermoregulatory responses to cognitive tasks regulated by DBA.
\end{abstract}

${ }^{*}$ Corresponding author.

How to cite this paper: Imai, E., Katagiri, Y., Hosaka, H. and Itao, K. (2016) Individual Differences in Cognitive Performance Regulated by Deep-Brain Activity during Mild Passive Hyperthermia and Neck Cooling. Journal of Behavioral and Brain Science, 6, 305-316. http://dx.doi.org/10.4236/jbbs.2016.68030 
Keywords

\author{
Cognitive Performance, Hyperthermia, Neck Cooling, Deep Brain, Electroencephalogram Alpha-2 \\ Rhythm
}

\title{
1. Introduction
}

Passive hyperthermia, associated with various conditions such as the neurological and physiological disorders rhabdomyolysis, multiple organ failure associated with hyperkalemia, myocardial infarction, is a typical risk factor to life in hot environments [1]-[9]. Hyperthermia-induced decline in cognitive performance is a more moderate but risky complication with respect to the maintenance of safety in a wide variety of fields. Under energy-saving restrictions in the workplace as global warming advances, even mild hyperthermia with no significant complications can be a risk factor for decreasing cognitive functions [10]-[12].

Previous studies have investigated impaired cognitive functions and behaviors during passive hyperthermia [13]-[15] and reported that such impairment is task dependent [16] and involves abnormalities in proactive brain functions primarily related to memory, judgment, and decision making. This dependency was attributed to limited cognitive resources [13] governed by task-specified regional combinations in the brain [17]-[19] with different thermal tolerances. In a more recent study [20], a brain network model was proposed and demonstrated using functional magnetic resonance imaging (MRI) techniques to explain the thermal fragility of proactive cognitive performance. This study identified the involvement of cortical regions and disruption of their functional connectivity during hyperthermia. The proposed large-scale network model includes default-mode, salience, and central executive networks [21] [22] that play a role in cognitive processing [23]-[26].

Although this network model may be useful for explaining some aspects of cognitive performance in normal and hot environments, its propensity remains unclear. Deep-brain activity (DBA) is known to be involved in both improved and degraded cognitive performance [27]-[29] and is involved in network connectivity [30]-[34]. DBA modulates the prefrontal cortex, which controls both cognitive processing [35] and depressive mood [36]. We hypothesized that individual differences in cognitive performance during hyperthermia are determined by the extent of activation of deep-brain function.

The primary aim of this study was to test our hypothesis by quantitatively evaluating the cognitive performance of healthy subjects in both normal and hot environments using the Continuous Performance Test (CPT) [37], which includes both proactive (AX-CPT) and reactive (SRT-CPT) tasks. Individual differences in response to heat were determined from the task performance as a function of the DBA index, which can be calculated from measured electroencephalogram (EEG) occipital alpha power [38] [39]. This dependency was also characterized using the State-Trait Anxiety Inventory (STAI) [40]-[42] to clarify how the propensity affects the cognitive performance during hyperthermia. From a practical perspective, hyperthermia-induced cognitive performance decline should be prevented. Previous studies have reported the beneficial effects of head or neck cooling on suppressing such decline [16]. On the other hand, cases have been reported in which cooling during exercise in hot environments has no significant effects on cognitive decline [43] [44]. Therefore, the second aim of the present study was to investigate the neurophysiological mechanisms that limit the cooling effects by assessing the physiological responses associated with cognitive behaviors.

\section{Materials and Methods}

\subsection{Subjects}

Student volunteers were recruited in Kobe Co-medical College for the present study. Fifteen healthy volunteers (12 female and 3 males; mean age, $28.1 \pm 4.8$ years) participated in the study after providing written informed consent. These participants were right handed and had no history of any psychopathological disorders or heat stroke. The participants completed the Japanese adaptation of the State-Trait Anxiety Inventory Form Y (STAI$\mathrm{JYZ}$ ) modified from the original form-Y before experiments in a calm environment with a room temperature of approximately $25^{\circ} \mathrm{C}$. The present study was approved by the Ethics Committee of the National Institute of Communication Technology. 


\subsection{Heat Exposure with/without Neck Cooling}

The participants were exposed to a hot environment by wearing an adiabatic thermal suit (Figure 1). The suit was originally designed for preventing hypothermia in extreme cold; thus, it was made using heat-insulating materials. This suit can increase the microclimate temperature using no heat source except the body heat of the participant. A deep-body thermometer based on the zero-heat-flow method [45] was attached to the middle of the forehead or planta to continuously monitor the core temperature. Each participant achieved a high microclimate temperature (above $30^{\circ} \mathrm{C}$ ) before the experiments were initiated (Figure 2).

This study employed a wearable neck-cooling system (Figure 3) comprising 3 major parts: a cooling collar, pipe lines, and a radiator. The collar was equipped with an electronically-controlled Peltier cooling device. Waste heat from the cooling device was removed through water-circulating pipelines and an air-cooling radiator. The collar was attached to the lateral and posterior parts of the neck for direct cooling of the bilateral carotid arteries. The core temperature at the forehead was promptly decreased by the neck-cooling system. A typical temperature response curve is shown in Figure 4 shows typical changes in brain temperature during neck cooling in the heat for randomly selected subjects. The brain temperature was defined as a core temperature measured at the middle of the forehead. The prompt temperature reduction was attributed to the bilateral arterial blood streams. This indicated that the neck-cooling system realized a type of selective brain cooling [46] [47].

\subsection{Battery of Cognitive Tasks and Error Analyses}

Subjects underwent a battery of cognitive tasks comprising SRT-CPT and AX-CPT tasks that were performed on a computer following the Conners' CPT. During the SRT-CPT task, subjects were required to press the button as quickly as possible every time a number was presented on the screen. Eighty stimuli comprising the same number "7" were presented at varying intervals. During the AX-CPT task, subjects were required to press the

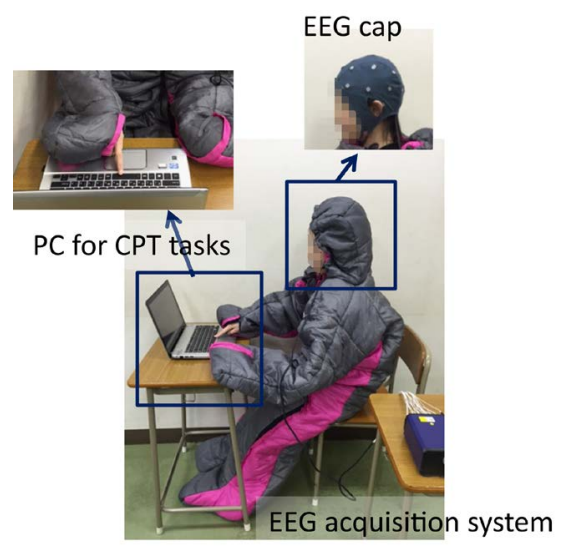

Figure 1. Experimental set-up for performing cognitive tasks in heat. The subject wore an adiabatic thermal suit equipped with a small window to hold out his/her finger to control the PC during CPT tasks.

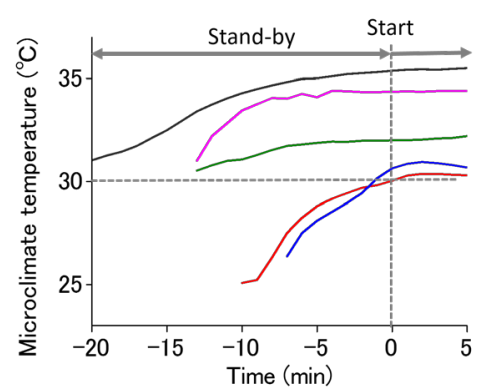

Figure 2. Microclimate temperature curves for a typical subject. Experiments start at Time $=0$. Variations of the final temperature were attributed to individual differences in metabolic rate. 


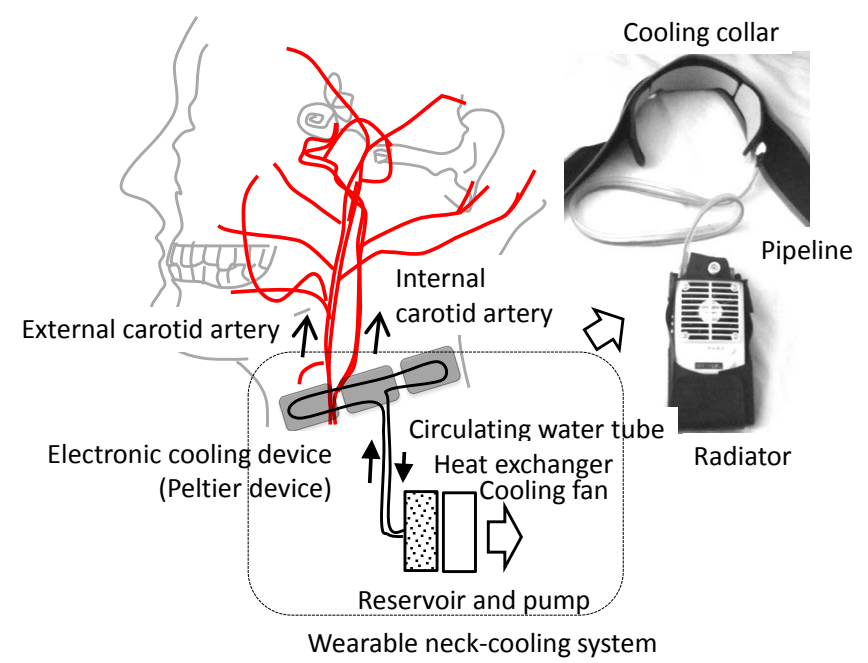

Figure 3. Schematic of the wearable neck-cooling system.

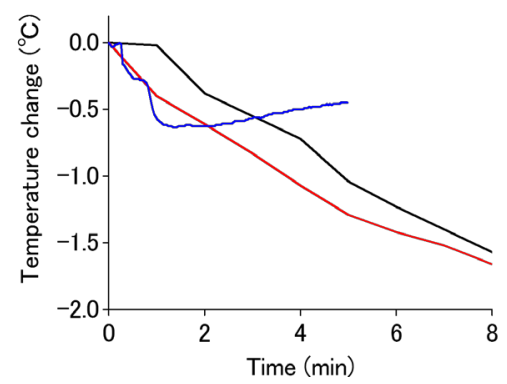

Figure 4. Changes in brain temperature measured at the middle of the forehead during neck cooling.

button as quickly as possible only when the number "7" appeared after the presentation of the number "3". Four-hundred number stimuli varying randomly from 1 to 9 , including 40 targets (3 - 7), were presented at varying intervals.

Errors were categorized as omission and commission errors. Although omission errors were detected based on a latency of $>1000 \mathrm{~ms}$ for the target stimuli, commission errors were detected based on a latency of $<100 \mathrm{~ms}$ for the target in both the SRT- and AX-CPT tasks. In addition, inadequate responses to non-target stimuli were also taken into account in the AX-CPT task.

\subsection{EEG Recording and Numerical Evaluation of DBA}

EEG was continuously recorded throughout the experiments. The recording was performed using a conventional international 10 - 20 system having $21 \mathrm{Ag} / \mathrm{AgCl}$ electrodes. Analog EEG signals acquired from the electrodes were digitized at $512 \mathrm{~Hz}$ with 24-bit ADC. Montage signals were produced from these digitized signals using the mastoid electrodes as a reference.

The EEG alpha-2 (10 - $13 \mathrm{~Hz})$ rhythm was dominant in the occipital region (Figure 5(a)). Time-series data of the occipital $(\mathrm{O} 1, \mathrm{O} 2)$ alpha-2 powers were calculated at every $31.25 \mathrm{~ms}$ from the fast Fourier transform using 2-s epoch EEG data at O1 and O2 electrodes. The average of these powers temporally fluctuated (Figure 5(b)). A slower component $(\leq 0.04 \mathrm{~Hz})$ of this fluctuation was defined as a DBA index.

\subsection{Statistical Analyses}

Statistical data processing was performed using the Student's t-test along the significant level set at $\mathrm{p}<0.05$ to examine significant changes in reaction time between normal and heat environments and neck-cooling effects. Correlation analyses were performed according to the conventional parametric method with Pearson's correlation 
(a)

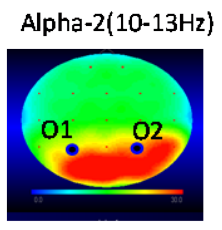

(b)

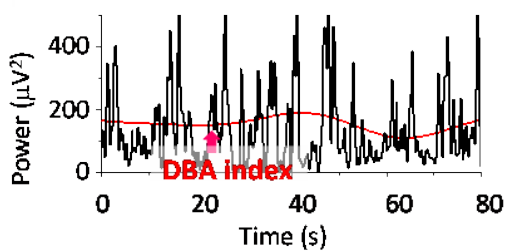

Figure 5. (a) Topographic map showing the alpha-2 (10 - $13 \mathrm{~Hz})$ rhythm dominant region; (b) Temporal waveform of the EEG occipital $(\mathrm{O} 1, \mathrm{O} 2)$ alpha-2 power was illustrated with the slower-component curve calculated from the temporal power waveform.

coefficients and corresponding probability values. Nonlinear relationships between two items were derived from the polynomial regression analyses.

\subsection{STAI Form-JYZ}

STAI-JYZ, as an advanced Japanese version [48] modified the original STAI-Y [49] precisely provides StateTrait anxiety measures using independent subscales related to positive and negative emotions. STAI-JYZ comprises 40 items, and subjects mark a rating from 1 to 4 for each item. The two anxiety measures are numerically evaluated in the range of 20 - 80 from their self-report answer sheets.

\subsection{Protocol}

The experimental protocol is shown in Figure 6. After completing the STAI questionnaire, subjects were fitted with an EEG cap and a sensor head at the middle of the forehead for core-temperature measurements. Subjects took rest for 5 min with eyes closed. The first battery of cognitive tasks comprising the SRT- and AX-CPT tasks was then completed. Subjects then wore the thermal suit and stood by for approximately 30 min until the microclimate temperature rose to a threshold of $30^{\circ} \mathrm{C}$. After confirming the required increase in temperature, HTgroup subjects promptly started the second battery of cognitive tasks, whereas the NC-group subjects turned on the neck-cooling system, rested for few minutes, and started the 20-min battery of tasks. EEG recording during cognitive tasks was performed with the eyes open. The experiment, requiring a total duration of approximately 2 h, was performed for each subject in the period between $3-6 \mathrm{pm}$.

\section{Results}

\subsection{Cognitive Performance}

All subjects made almost no errors during the simple reactive tasks (SRT-CPT), regardless of the ambient temperature being normal or hot. As shown in Figure 7(a), the error rate in the AX-CPT was higher in the lower DBA-index region for both omission and commission errors in a normal-temperature environment. In contrast, both omission and commission errors were lower in the NC-group subjects independent of the DBA index, whereas more errors appeared even in a higher DBA-index range for HT-group subjects in hot environments. These aspects were accentuated in the results of correlation analyses for logarithmic error rate vs. DBA index with excluding error-free data, as shown in Figure 7(b). The reaction time (RT) in SRT- and AX-CPT tasks did not change significantly between normal and hot environments, regardless of whether neck cooling was used (Figure 8).

\subsection{DBA in Cognitive Tasks in Hot Environment with/without Neck Cooling}

As shown in Figure 9, neck cooling increased the average DBA index during cognitive tasks. The increase was 


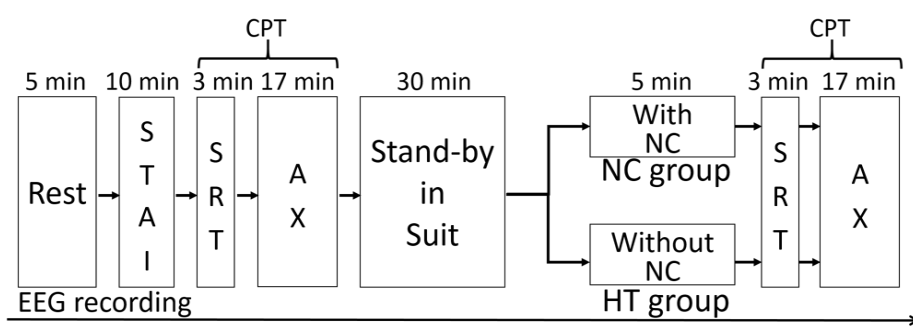

Figure 6. Experimental protocol.

(a)
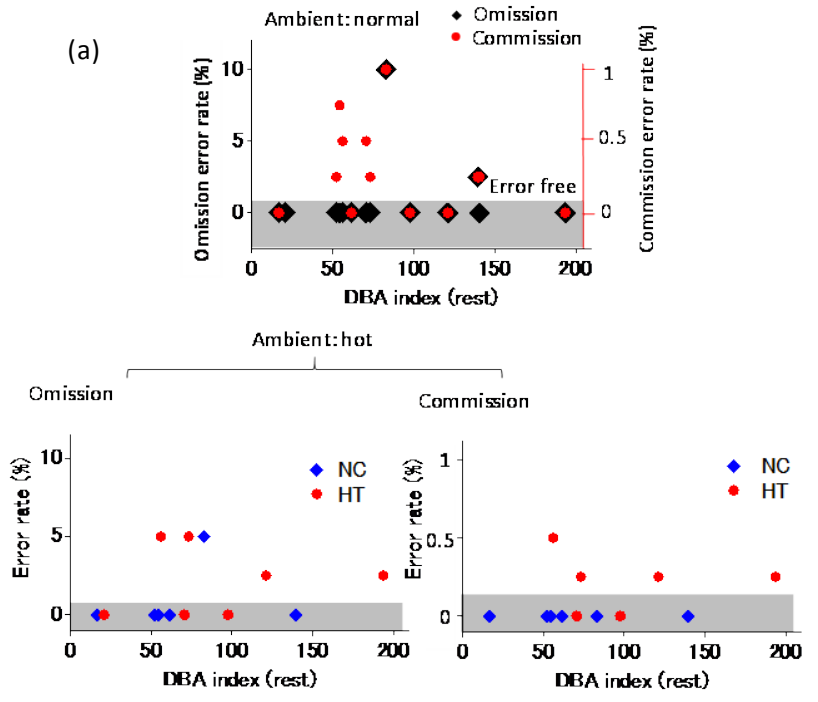

Figure 7. (a) AX-CPT error rate vs. average DBA index at rest in normal (temperature $=25^{\circ} \mathrm{C}$ ) and hot (temperature $\leq 30^{\circ} \mathrm{C}$ ) environments; (b) Correlation analyses of logarithmic total error rate (omission + commission) vs. DBA index (rest). Error-free data were excluded. Although correlation analyses did not reach statistical significance, it was found that impairment of cognitive performance in the heat can be reduced with DBA increasing. Furthermore, neck cooling is beneficial for maintaining cognitive performance in the heat.

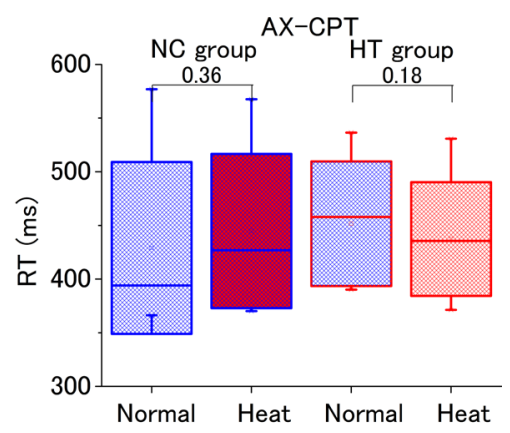

(a)

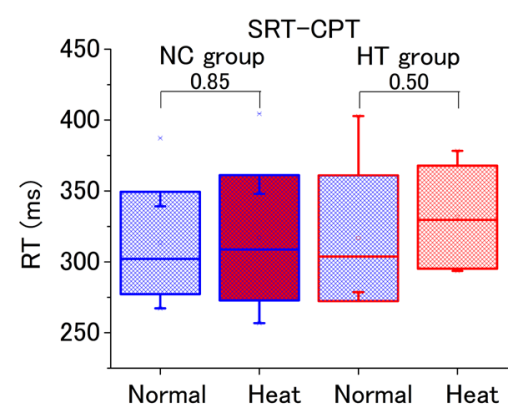

(b)

Figure 8. Reaction time changes in SRT- and AX-CPT tasks between normal (temperature $=25^{\circ} \mathrm{C}$ ) and hot (temperature $\leq 30^{\circ} \mathrm{C}$ ) environments.

greater for subjects with higher average DBA indices at rest. This relationship was more significant for AX-CPT than SRT-CPT.

\subsection{STAI and DBA}

State- and traitanxiety were independently evaluated from self-reports of STAI. Subjects exhibited a linear relationship between these anxiety measures (Figure 10(a)). Trait anxiety was used as an index for characterizing 


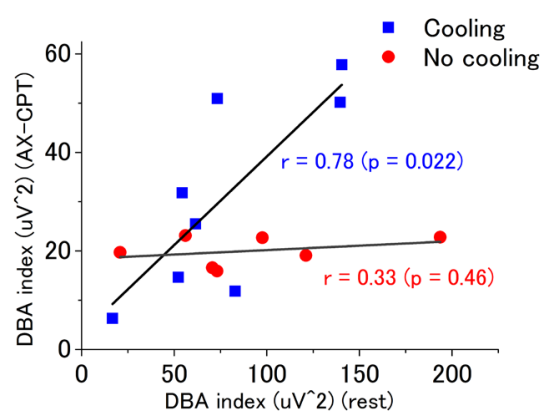

(a)

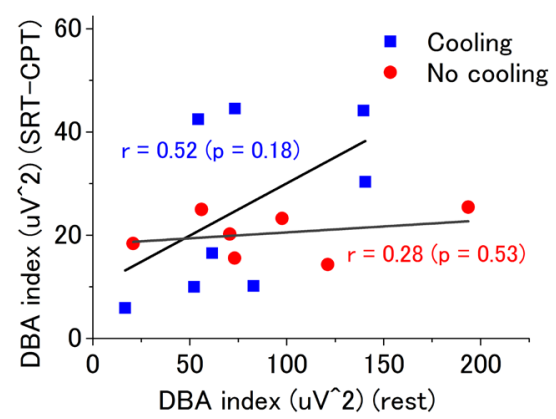

(b)

Figure 9. Neck-cooling effects on average DBA index during cognitive task vs. average DBA index at rest for (a) AX-CPT and (b) SRT-CPT.

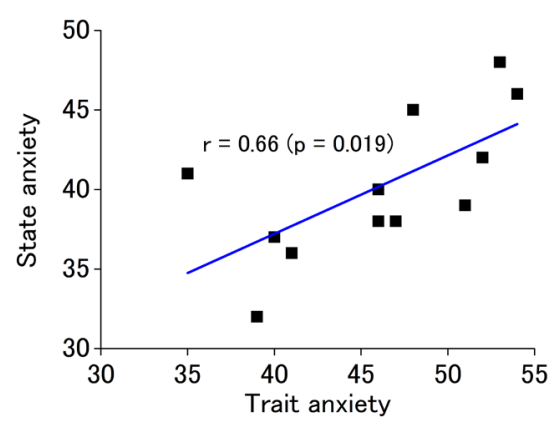

(a)

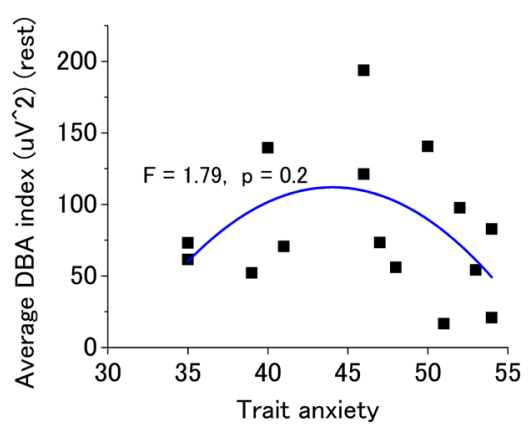

(b)

Figure 10. (a) State anxiety vs. trait anxiety and (b) average DBA index vs. trait anxiety. The 2nd-order fitting curve was derived from the polynomial regression analyses.

propensity in cognitive performance and behaviors. As shown in Figure 10(b), the average DBA index decreased in both higher and lower trait-anxiety regions, although it had been expected that the DBA would exhibit a simple negative correlation with trait anxiety.

\subsection{Thermoregulatory Responses to Cognitive Tasks during Heat Exposure and Neck-Cooling Effects}

Thermoregulatory responses of subjects to cognitive tasks were investigated during heat exposure by continuously monitoring the microclimate and core temperatures. Figure 11(a) shows a case with neck cooling. The core temperature promptly increased as soon as the task began, whereas the microclimate temperature decreased. These 2 temperature responses were reciprocal. The core temperature reached a peak and then decreased, whereas the microclimate temperature remained at the minimum. In contrast, as shown in Figure 11(b), a case with no neck cooling exhibited a much different profile, with the microclimate temperature slowly increasing and the core temperature rise lagging, independent of task performance.

\section{Discussion}

Our results indicate that a higher average DBA index during tasks is essential for high cognitive performance in the heat. As reported by a previous study [38], slower components of the DBA index (frequencies below 0.04 $\mathrm{Hz}$ ) reflect the activity of the upper brainstem, including monoaminergic neural systems, whereas faster components reflect the involvement of other deep-brain structures, including the thalamus. Such frequency analyses of the DBA index are reliable as shown by simultaneous EEG and functional magnetic resonance imaging (fMRI) measurements in previous studies presenting positive [50]-[52] or negative [53] [54] correlations between EEG occipital alpha powers and regional blood oxygen level dependent signals. The monoaminergic neural systems belong to the upper brainstem, modulating the PFC associated with cognitive processing and reward [55]-[57]. Because the average DBA index reflects slower components, the beneficial effect of DBA found in the present 


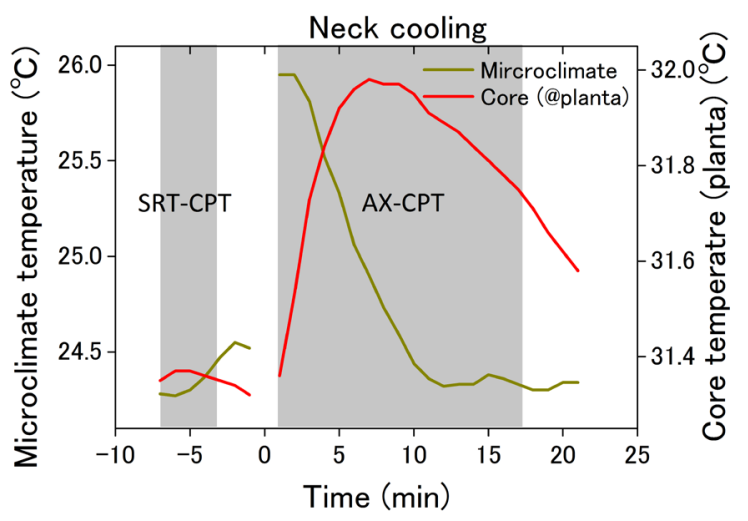

(a)

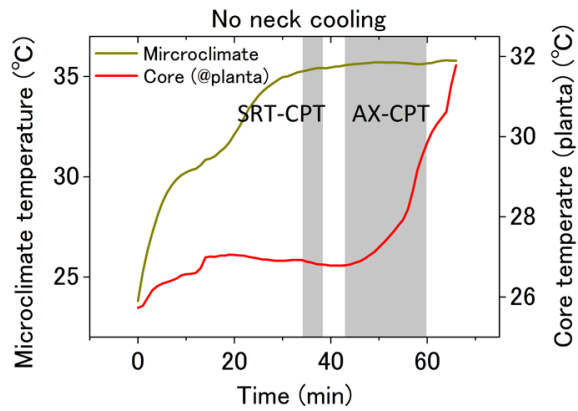

(b)

Figure 11. Responses of core and microclimate temperatures to cognitive tasks during heat exposure using a thermal suit with (a) neck cooling, and (b) no cooling.

study is governed by the upper brainstem.

This DBA benefit is more significant in individuals with higher average DBA indices at rest in a normal environment. The average DBA index at rest correlates with trait anxiety extracted from the STAI battery. Hence, the maintenance of cognitive performance in the heat can be assessed using the average DBA index. We also found that the beneficial DBA effect on cognitive performance in heat only occurs for the conditions involving neck cooling. However, as reported in some previous studies, neck cooling does not prevent the decline in cognitive performance during severe hyperthermia [58] [59]. This discrepancy indicates that the beneficial neckcooling effect is limited to mild hyperthermia. We consider that this limitation is attributed to thermoregulatory responses to cognitive tasks regulated by DBA.

Our results show that the core temperature increases during tasks. This temperature increase corresponds to increased cerebral blood flow (CBF). DBA may allocate processing for cognitive tasks as a top priority, thereby increasing CBF [60] and metabolic rate [61] and suppressing homeostatic thermoregulatory responses to hyperthermia. Such anti-homeostatic DBA behavior may be disabled in severe hyperthermia, resulting in decreased CBF [62] [63] because of a strong demand on the hypothalamus, with the first priority being life. It is possible to enhance such anti-homeostatic DBA function with dopamine releasing [64]. However, this method is accompanied by a risk of hyperthermia and related grave complications.

The present study was not without some limitations. First, the experiments were limited to healthy subjects. Consequently, they exhibited limited STAI scores of $46 \pm 6.5$. To confirm our hypothesis in clinical fields, subjects with much higher or lower STAI scores will have to be investigated, although such subjects have risks of some diseases including depression or attention deficit hyperactivity disorder. Second, the present study cannot exclude sex differences in the individual differences. Such differences may come from not only higher-order brain functions associated with emotional processing but also physiological systems including the endocrine system. Before discussing sex differences, it will be necessary for elucidating the role of these fundamental physiological systems in cognitive performance and behaviors.

\section{Conclusion}

We have explored the primary role of DBA in the maintenance of cognitive performance during mild hyperthermia to elucidate the neurophysiological mechanisms underlying task-dependent cognitive performance in heat. Our findings will be clinically useful not only for assessing the risk of hyperthermia-induced cognitive dysfunction but also for developing effective procedures to prevent such dysfunction in patients with deep-brain structure pathologies.

\section{Acknowledgements}

The study was partially supported by Japan New Energy and Industrial Technology Development Organization (NEDO) and Japan Society for the Promotion of Science ((C) 25420236). 


\section{References}

[1] Kiyatkin, E.A. (2005) Brain Hyperthermia as Physiological and Pathological Phenomena. Brain Research Reviews, 50, 27-56. http://dx.doi.org/10.1016/j.brainresrev.2005.04.001

[2] Carvalho, A.S., Rodeia, S.C., Silvestre, J. and Póvoa, P. (2016) Exertional Heat Stroke and Acute Liver Failure: A Late Dysfunction. BMJ Case Reports. http://dx.doi.org/10.1136/bcr-2016-214434

[3] Kalita, J. and Misra, U.K. (2001) Neurophysiological Studies in a Patient with Heat Stroke. Journal of Neurology, 248, 993-995. http://dx.doi.org/10.1007/s004150170056

[4] Yankelson, L., Sadeh, B., Gershovitz, L., Werthein, J., Heller, K., Halpern, P., Halkin, A., Adler, A., Steinvil, A. and Viskin, S. (2014) Life-Threatening Events during Endurance Sports: Is Heat Stroke More Prevalent Than Arrhythmic Death? Journal of the American College of Cardiology, 64, 463-469. http://dx.doi.org/10.1016/j.jacc.2014.05.025

[5] Chen, W.T., Lin, C.H., Hsieh, M.H., Huang, C.Y. and Yeh, J.S. (2012) Stress-Induced Cardiomyopathy Caused by Heat Stroke. Annals of Emergency Medicine, 60, 63-66. http://dx.doi.org/10.1016/j.annemergmed.2011.11.005

[6] Thomas, J. and Crowhurst, T. (2013) Exertional Heat Stroke, Rhabdomyolysis and Susceptibility to Malignant Hyperthermia. Internal Medicine Journal, 43, 1035-1038. http://dx.doi.org/10.1111/imj.12232

[7] Azzopardi, N., Chetcuti, S., Sant, J. and Pocock, J. (2012) Acute Liver Impairment in a Young, Healthy Athlete: Hypoxic Hepatitis and Rhabdomyolysis Following Heat Stroke. Case Reports in Gastroenterology, 6, 563-568. http://dx.doi.org/10.1159/000338838

[8] Trujillo, M.H. and Fragachán, G.C. (2011) Rhabdomyolysis and Acute Kidney Injury Due to Severe Heat Stroke. Case Reports in Critical Care. http://dx.doi.org/10.1155/2011/951719

[9] Asserraji, M., Benameur, I., Maoujoud, O., El Kharras, A., Hajbi, H. and Filali, K. (2014) Late Care in Marathon Runs Leading to Exertional Heat Stroke with Multiple Organ Failure. Asian Journal of Sports Medicine, 5, 136-138.

[10] Taylor, L., Watkins, S.L., Marshall, H., Dascombe, B.J. and Foster, J. (2016) The Impact of Different Environmental Conditions on Cognitive Function: A Focused Review. Frontiers in Physiology. http://dx.doi.org/10.3389/fphys.2015.00372

[11] Balogun, A.A., Balogun, I.A. and Adeyewa, Z.D. (2010) Comparisons of Urban and Rural Heat Stress Conditions in a Hot-Humid Tropical City. Global Health Action, 3, 5614. http://dx.doi.org/10.3402/gha.v3i0.5614

[12] Berg, R.J., Inaba, K., Sullivan, M., Okoye, O., Siboni, S., Minneti, M., Teixeira, P.G. and Demetriades, D. (2015) The Impact of Heat Stress on Operative Performance and Cognitive Function during Simulated Laparoscopic Operative Tasks. Surgery, 157, 87-95. http://dx.doi.org/10.1016/j.surg.2014.06.012

[13] Hancock, P.A. (1986) Sustained Attention under Thermal Stress. Psychological Bulletin, 99, 263-281. http://dx.doi.org/10.1037/0033-2909.99.2.263

[14] Hocking, C., Silberstein, R.B., Lau, W.M., Stough, C. and Roberts, W. (2001) Evaluation of Cognitive Performance in the Heat by Functional Brain Imaging and Psychometric Testing. Comparative Biochemistry and Physiology Part A: Molecular \& Integrative Physiology, 128, 719-734. http://dx.doi.org/10.1016/S1095-6433(01)00278-1

[15] Hancock, P.A. and Vasmatzidis, I. (2003) Effects of Heat Stress on Cognitive Performance: The Current State of Knowledge. International Journal of Hyperthermia, 19, 355-732. http://dx.doi.org/10.1080/0265673021000054630

[16] Gaoa, N.1., Racinais, S., Grantham, J. and El Massioui, F. (2011) Alterations in Cognitive Performance during Passive Hyperthermia Are Task Dependent. International Journal of Hyperthermia, 27, 1-9. http://dx.doi.org/10.3109/02656736.2010.516305

[17] Liu, K., Li, B., Qian, S., Jiang, Q., Li, L. and Sun, G. (2015) Altered Interhemispheric Resting State Functional Connectivity during Passive Hyperthermia. International Journal of Hyperthermia, 31, 840-849. http://dx.doi.org/10.3109/02656736.2015.1058977

[18] Posner, M.I., Sheese, B.E., Odludaş, Y. and Tang, Y. (2006) Analyzing and Shaping Human Attentional Networks. Neural Networks, 19, 1422-1429. http://dx.doi.org/10.1016/j.neunet.2006.08.004

[19] Duann, J.R, Ide, J.S., Luo, X. and Li, C.S. (2009) Functional Connectivity Delineates Distinct Roles of the Inferior Frontal Cortex and Presupplementary Motor Area in Stop Signal Inhibition. The Journal of Neuroscience, 29, 1017110179. http://dx.doi.org/10.1523/JNEUROSCI.1300-09.2009

[20] Sun, G., Qian, S., Jiang, Q., Liu, K., Li, B., Li, M., Zhao, L., Zhou, Z., von Deneen, K.M. and Liu, Y. (2013) Hyperthermia-Induced Disruption of Functional Connectivity in the Human Brain Network. PLoS ONE, 8, e61157. http://dx.doi.org/10.1371/journal.pone.0061157

[21] Raichle, M.E., MacLeod, A.M., Snyder, A.Z., Powers, W.J., Gusnard, D.A. and Shulman, G.L. (2001) A Default Mode of Brain Function. Proceedings of the National Academy of Sciences of the United States of America, 98, 676-682. http://dx.doi.org/10.1073/pnas.98.2.676 
[22] Menon, V. (2011) Large-Scale Brain Networks and Psychopathology: A Unifying Triple Network Model. Trends in Cognitive Sciences, 15, 483-506. http://dx.doi.org/10.1016/j.tics.2011.08.003

[23] Leech, R. and Sharp, D.J. (2014) The Role of the Posterior Cingulate Cortex in Cognition and Disease. Brain, 137, 1232. http://dx.doi.org/10.1093/brain/awt162

[24] Menon, V. and Uddin, L.Q. (2010) Saliency, Switching, Attention and Control: A Network Model of Insula Function. Brain Structure and Function, 214, 655-667. http://dx.doi.org/10.1007/s00429-010-0262-0

[25] Laufs, H., Krakow, K., Sterzer, P., Eger, E., Beyerle, A., Salek-Haddadi, A. and Kleinschmidt, A. (2003) Electroencephalographic Signatures of Attentional and Cognitive Default Modes in Spontaneous Brain Activity Fluctuations at Rest. Proceedings of the National Academy of Sciences of the United States of America, 100, 11053-11058. http://dx.doi.org/10.1073/pnas.1831638100

[26] Dosenbach, N.U., Fair, D.A., Miezin, F.M., Cohen, A.L., Wenger, K.K., Dosenbach, R.A., Fox, M.D., Snyder, A.Z., Vincent, J.L., Raichle, M.E., Schlaggar, B.L. and Petersen, S.E. (2007) Distinct Brain Networks for Adaptive and Stable Task Control in Humans. Proceedings of the National Academy of Sciences of the United States of America, 104, 11073-11078. http://dx.doi.org/10.1073/pnas.0704320104

[27] Hazy, T.E., Frank, M.J. and O’Reilly, R.C. (2010) Neural Mechanisms of Acquired Phasic Dopamine Responses in Learning. Neuroscience \& Biobehavioral Reviews, 34, 701-720. http://dx.doi.org/10.1016/j.neubiorev.2009.11.019

[28] Krebs, R.M., Boehler, C.N., Roberts, K.C., Song, A.W. and Woldorff, M.G. (2012) The Involvement of the Dopaminergic Midbrain and Cortico-Striatal-Thalamic Circuits in the Integration of Reward Prospect and Attentional Task Demands. Cerebral Cortex, 22, 607-615. http://dx.doi.org/10.1093/cercor/bhr134

[29] Guthrie, M., Myers, C.E. and Gluck, M.A. (2009) Aneurocomputational Model of Tonic and Phasic Dopamine in Action Selection: A Comparison with Cognitive Deficits in Parkinson's Disease. Behavioral Brain Research, 200, 48-59. http://dx.doi.org/10.1016/j.bbr.2008.12.036

[30] Cole, D.M., Oei, N.Y., Soeter, R.P., Both, S., van Gerven, J.M., Rombouts, S.A. and Beckmann, C.F. (2013) Dopamine-Dependent Architecture of Cortico-Subcortical Network Connectivity. Cerebral Cortex, 23, 1509-1516. http://dx.doi.org/10.1093/cercor/bhs136

[31] Hwang, J., Xin, S.C., Ou, Y.M., Zhang, W.Y., Liang, Y.L., Chen, J., Yang, X.Q., Chen, X.Y., Guo, T.W., Yang, X.J., Ma, W.H., Li, J., Zhao, B.C., Tu, Y. and Kong, J. (2016) Enhanced Default Mode Network Connectivity with Ventral Striatum in Subthreshold Depression Individuals. Journal of Psychiatric Research, 76, 111-120. http://dx.doi.org/10.1016/j.jpsychires.2016.02.005

[32] Assadi, S.M., Yücel, M. and Pantelis, C. (2009) Dopamine Modulates Neural Networks Involved in Effort-Based Decision-Making. Neuroscience \& Behavioral Review, 33, 383-393. http://dx.doi.org/10.1016/j.neubiorev.2008.10.010

[33] Cole, D.M., Beckmann, C.F., Oei, N.Y., Both, S., van Gerven, J.M. and Rombouts, S.A. (2013) Differential and Distributed Effects of Dopamine Neuromodulations on Resting-State Network Connectivity. Neuroimage, 78, 59-67. http://dx.doi.org/10.1016/j.neuroimage.2013.04.034

[34] Liddle, E.B., Hollis, C., Batty, M.J., Groom, M.J., Totman, J.J., Liotti, M., Scerif, G. and Liddle, P.F. (2011) Task-Related Default Mode Network Modulation and Inhibitory Control in ADHD: Effects of Motivation and Methylphenidate. The Journal of Child Psychology and Psychiatry, 52, 761-771. http://dx.doi.org/10.1111/j.1469-7610.2010.02333.x

[35] Braver, T.S., Paxton, J.L., Locke, H.S. and Barch, D.M. (2009) Flexible Neural Mechanisms of Cognitive Control within Human Prefrontal Cortex. Proceedings of the National Academy of Sciences of the United States of America, 106, 7351-7356. http://dx.doi.org/10.1073/pnas.0808187106

[36] Mayberg, H.S. (2009) Targeted Electrode-Based Modulation of Neural Circuits for Depression. The Journal of Clinical Investigation, 119, 717-725. http://dx.doi.org/10.1172/JCI38454

[37] Tana, M.G., Montin, E., Cerutti, S. and Bianchi, A.M. (2010) Exploring Cortical Attentional System by Using fMRI during a Continuous Perfomance Test. Computational Intelligence and Neuroscience, 2010, Article ID: 329213. http://dx.doi.org/10.1155/2010/329213

[38] Omata, K., Hanakawa, T., Morimoto, M. and Honda, M. (2013) Spontaneous Slow Fluctuation of EEG Alpha Rhythm Reflects Activity in Deep-Brain Structures: A Simultaneous EEG-fMRI Study. PLoS ONE, 8, e66869. http://dx.doi.org/10.1371/journal.pone.0066869

[39] Bohgaki, T., Katagiri, Y. and Usami, M. (2014) Pain-Relief Effects of Aroma Touch Therapy with Citrus Junos Oil Evaluated by Quantitative EEG Occipital Alpha-2 Rhythm Powers. Journal of Behavioral and Brain Science, 4, 43-48. http://dx.doi.org/10.4236/jbbs.2014.41002

[40] Julian, L.J. (2011) Measures of Anxiety: State-Trait Anxiety Inventory (STAI), Beck Anxiety Inventory (BAI), and Hospital Anxiety and Depression Scale-Anxiety (HADS-A). Arthritis Care \& Research, 63, S467-S472. http://dx.doi.org/10.1002/acr.20561 
[41] Seligman, L.D., Ollendick, T.H., Langley, A.K. and Baldacci, H.B. (2004) The Utility of Measures of Child and Adolescent Anxiety: A Meta-Analytic Review of the Revised Children's Manifest Anxiety Scale, the State-Trait Anxiety Inventory for Children, and the Child Behavior Checklist. Journal of Clinical Child \& Adolescent Psychology, 33, 557565. http://dx.doi.org/10.1207/s15374424jccp3303_13

[42] Kennedy, B.L., Schwab, J.J., Morris, R.L. and Beldia, G. (2001) Assessment of State and Trait Anxiety in Subjects with Anxiety and Depressive Disorders. Psychiatric Quarterly, 72, 263-276. http://dx.doi.org/10.1023/A:1010305200087

[43] Simmons, S.E., Saxby, B.K., McGlone, F.P. and Jones, D.A. (2008) The Effect of Passive Heating and Head Cooling on Perception, Cardiovascular Function and Cognitive Performance in the Heat. European Journal of Applied Physiology, 104, 271-280. http://dx.doi.org/10.1007/s00421-008-0677-y

[44] Ando, S., Komiyama, T., Sudo, M., Kiyonaga, A., Tanaka, H. and Higaki, Y. (2015) The Effects of Temporal Neck Cooling on Cognitive Function during Strenuous Exercise in a Hot Environment: A Pilot Study. BMC Research Notes, 8, 202. http://dx.doi.org/10.1186/s13104-015-1210-0

[45] Kobayashi, T., Nemoto, T., Kamiya, A. and Togawa, T. (1975) Improvement of Deep Body Thermometer for Man. Annals of Biomedical Engineering, 3, 181-188. http://dx.doi.org/10.1007/BF02363069

[46] Cabanac, M. and Caputa, M. (1979) Open Loop Increase in Trunk Temperature Produced by Face Cooling in Working Humans. The Journal of Physiology, 89, 163-174. http://dx.doi.org/10.1113/jphysiol.1979.sp012730

[47] Cabanac, M. and Caputa, M. (1979) Natural Selective Cooling of the Human Brain: Evidence of Its Occurrence and Magnitude. The Journal of Physiology, 286, 255-264. http://dx.doi.org/10.1113/jphysiol.1979.sp012617

[48] Iwata, N., Mishima, N., Shimizu, T., Mizoue, T., Fukuhara, M., Hidano, T. and Spielberger, C.D. (1998) The Japanese Adaptation of the STAI Form Y in Japanese Working Adults-The Presence or Absence of Anxiety. Industrial Health, 36, 8-13. http://dx.doi.org/10.2486/indhealth.36.8

[49] Spielberger, C.D. (1983) Manual for the State-Trait Anxiety Inventory, STAI-Form Y. Consulting Psychologies Press, Palo Alto.

[50] Sadato, N., Nakamura, S., Oohashi, T., Nishina, E., Fuwamoto, Y., Waki, A. and Yonekura, Y. (1998) Neural Networks for Generation and Suppression of Alpha Rhythm: A PET Study. Neuroreport, 30, 893-897. http://dx.doi.org/10.1097/00001756-199803300-00024

[51] Goldman, R.I., Stern, J.M., Engel Jr., J. and Cohen. M.S. (2002) Simultaneous EEG and fMRI of the Alpha Rhythm. Neuroreport, 13, 2487-2492. http://dx.doi.org/10.1097/00001756-200212200-00022

[52] Schreckenberger, M., Lange-Asschenfeldt, C., Lochmann, M., Mann, K., Siessmeier, T., Buchholz, H.G., Bartenstein, P. and Gründer, G. (2004) The Thalamus as the Generator and Modulator of EEG Alpha Rhythm: A Combined PET/EEG Study with Lorazepam Challenge in Humans. Neuroimage, 22, 637-644. http://dx.doi.org/10.1016/j.neuroimage.2004.01.047

[53] Larson, C.L., Davidson, R.J., Abercrombie, H.C., Ward, R.T., Schaefer, S.M., Jackson, D.C., Holden, J.E. and Perlman, S.B. (1998) Relations between PET-Derived Measures of Thalamic Glucose Metabolism and EEG Alpha Power. Psychophysiology, 35, 162-169. http://dx.doi.org/10.1111/1469-8986.3520162

[54] Lindgren, K.A., Larson, C.L., Schaefer, S.M., Abercrombie, H.C., Ward, R.T., Oakes, T.R., Holden, J.E., Perlman, S.B., Benca, R.M. and Davidson, R.J. (1999) Thalamic Metabolic Rate Predicts EEG Alpha Power in Healthy Control Subjects but Not in Depressed Patients. Biological Psychiatry, 45, 943-952. http://dx.doi.org/10.1016/S0006-3223(98)00350-3

[55] Hwang, J.W., Xin, S.C., Ou, Y.M., Zhang, W.Y., Liang, Y.L., Chen, J., Yang, X.Q., Chen, X.Y., Guo, T.W., Yang, X.J., Ma, W.H., Li, J., Zhao, B.C., Tu, Y. and Kong, J. (2016) Enhanced Default Mode Network Connectivity with Ventral Striatum in Subthreshold Depression Individuals. Journal of Psychiatric Research, 76, 111-120. http://dx.doi.org/10.1016/j.jpsychires.2016.02.005

[56] Schrantee, A., Ferguson, B., Stoffers, D., Booij, J., Rombouts, S. and Reneman, L. (2015) Effects of DexamphetamineInduced Dopamine Release on Resting-State Network Connectivity in Recreational Amphetamine Users and Healthy Controls. Brain Imaging and Behavior, 2015, 1-11.

[57] Cole, D.M., Beckmann, C.F., Oei, N.Y., Both, S., van Gerven, J.M. and Rombouts, S.A. (2013) Differential and Distributed Effects of Dopamine Neuromodulations on Resting-State Network Connectivity. Neuroimage, 78, 59-67. http://dx.doi.org/10.1016/j.neuroimage.2013.04.034

[58] Simmons, S.E., Saxby, B.K., McGlone, F.P. and Jones, D.A. (2008) The Effect of Passive Heating and Head Cooling on Perception, Cardiovascular Function and Cognitive Performance in the Heat. European Journal of Applied Physiology, 104, 271-280. http://dx.doi.org/10.1007/s00421-008-0677-y

[59] Ando, S., Komiyama, T., Sudo, M., Kiyonaga, A., Tanaka, H. and Higaki, Y. (2015) The Effects of Temporal Neck Cooling on Cognitive Function during Strenuous Exercise in a Hot Environment: A Pilot Study. BMC Research Notes, 


\section{8, 202. http://dx.doi.org/10.1186/s13104-015-1210-0}

[60] Faulkner, H.G., Myrden, A., Li, M.,Mamun, K. and Chau, T. (2015) Sequential Hypothesis Testing for Automatic Detection of Task-Related Changes in Cerebral Perfusion in a Brain-Computer Interface. Neuroscience Research, 100, 29-38. http://dx.doi.org/10.1016/j.neures.2015.06.007

[61] Kataoka, N., Hioki, H., Kaneko, T. and Nakamura, K. (2014) Psychological Stress Activates a Dorsomedial Hypothalamus-Medullary Raphe Circuit Driving Brown Adipose Tissue Thermogenesis and Hyperthermia. Cell Metabolism, 20, 346-358. http://dx.doi.org/10.1016/j.cmet.2014.05.018

[62] Qian, S., Jiang, Q., Liu, K., Li, B., Li, M., Li, L., Yang, X., Yang, Z. and Sun, G. (2014) Effects of Short-Term Environmental Hyperthermia on Patterns of Cerebral Blood Flow. Physiology \& Behavior, 128, 99-107. http://dx.doi.org/10.1016/j.physbeh.2014.01.028

[63] Nybo, L. and Nielsen, B. (2001) Middle Cerebral Artery Blood Velocity Is Reduced with Hyperthermia during Prolonged Exercise in Humans. The Journal of Physiology, 534, 279-286. http://dx.doi.org/10.1111/j.1469-7793.2001.t01-1-00279.x

[64] Roelands, B., De Pauw, K. and Meeusen, R. (2015) Neurophysiological Effects of Exercise in the Heat. Scandinavian Journal of Medicine \& Science in Sports, 25, 65-78. http://dx.doi.org/10.1111/sms.12350

\section{Submit or recommend next manuscript to SCIRP and we will provide best service for you:}

Accepting pre-submission inquiries through Email, Facebook, Linkedin, Twitter, etc A wide selection of journals (inclusive of 9 subjects, more than 200 journals)

Providing a 24-hour high-quality service

User-friendly online submission system

Fair and swift peer-review system

Efficient typesetting and proofreading procedure

Display of the result of downloads and visits, as well as the number of cited articles

Maximum dissemination of your research work

Submit your manuscript at: http://papersubmission.scirp.org/ 